Liver, Pancreas and Biliary Tract

\title{
Hepatitis C virus RNA levels at week-2 of telaprevir/boceprevir administration are predictive of virological outcome
}

\author{
Valeria Cento ${ }^{\mathrm{a}}$, Daniele Di Paolo ${ }^{\mathrm{b}}$, Domenico Di Carlo ${ }^{\mathrm{a}}$, Valeria Micheli ${ }^{\mathrm{c}}$, \\ Monica Tontodonati ${ }^{\mathrm{d}, \mathrm{e}}$, Francesco De Leonardis ${ }^{\mathrm{b}}$, Marianna Aragri ${ }^{\mathrm{a}}$, \\ Giuliano Rizzardini ${ }^{\mathrm{l}}$, Mario Angelico ${ }^{\mathrm{b}}$, Carlo Federico Perno ${ }^{\mathrm{a}}$, \\ Francesca Ceccherini-Silberstein ${ }^{\mathrm{a}, *}$ \\ a Department of Experimental Medicine and Surgery, University of Rome "Tor Vergata", Rome, Italy \\ ${ }^{\mathrm{b}}$ Hepatology Unit, University Hospital of Rome "Tor Vergata", Rome, Italy \\ ' Unit of Microbiology, Hospital Sacco of Milan, Milan, Italy \\ ${ }^{d}$ Infectious Disease Clinic, Chieti, Italy \\ e Infectious Disease Unit, Pescara General Hospital, Pescara, Italy \\ ${ }^{\mathrm{f}}$ Infectious Diseases Unit, Department of Clinical and Experimental Medicine, University of Sassari, Italy \\ g "La Sapienza" University, Rome, Italy \\ h S. Martino Hospital, Genova, Italy \\ i Hepatology Unit, National Institute of Health, Migration and Poverty, Rome, Italy \\ ${ }^{\mathrm{j}}$ Infectious Disease, University Hospital of Rome "Tor Vergata”, Rome, Italy \\ ${ }^{\mathrm{k}}$ Gastroenterology, Catholic University of Rome, Rome, Italy \\ ${ }^{1}$ Division of Infectious Disease, Hospital Sacco of Milan, Milan, Italy \\ ${ }^{\mathrm{m}}$ Hepatology Unit, San Camillo Forlanini Hospital, Rome, Italy
} Francesco Paolo Antonucci ${ }^{a}$, Velia Chiara Di Maio ${ }^{a}$, Alessandro Mancon ${ }^{c}$, Ilaria Lenci ${ }^{b}$, Alessandra Manunta ${ }^{\mathrm{f}}$, Gloria Taliani ${ }^{\mathrm{g}}$, Antonio Di Biagio ${ }^{\mathrm{h}}$, Laura Ambra Nicolini ${ }^{\mathrm{h}}$, Lorenzo Nosotti $^{i}$, Cesare Sarrecchia ${ }^{j}$, Massimo Siciliano ${ }^{k}$, Simona Landonio ${ }^{1}$, Adriano Pellicelli ${ }^{\mathrm{m}}$, Adriano Gasbarrini ${ }^{\mathrm{k}}$, Jacopo Vecchiet ${ }^{\mathrm{d}}$, Carlo Federico Magni ${ }^{1}$, Sergio Babudieri ${ }^{\mathrm{f}}$, Maria Stella Mura ${ }^{\mathrm{f}}$, Massimo Andreoni ${ }^{\mathrm{j}}$, Giustino Parruti ${ }^{\mathrm{e}}$,

\section{A R T I C L E I N F O}

\section{Article history:}

Received 8 July 2014

Accepted 18 November 2014

Available online $\mathrm{xxx}$

\section{Keywords:}

Early response

NS3 protease inhibitors

Viral kinetics

Virological failure

\begin{abstract}
A B S T R A C T
Background: Triple therapy with telaprevir/boceprevir + pegylated-interferon + ribavirin can achieve excellent antiviral efficacy, but it can be burdened with resistance development at failure.

Aims: To evaluate kinetics of hepatitis C virus (HCV) RNA decay and early resistance development, in order to promptly identify patients at highest risk of failure to first generation protease inhibitors.

Methods: HCV-RNA was prospectively quantified in 158 patients receiving pegylatedinterferon + ribavirin + telaprevir $(N=114)$ or + boceprevir $(N=44)$, at early time-points and during per protocol follow-up. Drug resistance was contextually evaluated by population sequencing.

Results: HCV-RNA at week-2 was significantly higher in patients experiencing virological failure to triple-therapy than in patients with sustained viral response $(2.3[1.9-2.8]$ versus $1.2[0.3-1.7] \log \mathrm{IU} / \mathrm{mL}$, $p<0.001$ ). A $100 \mathrm{IU} / \mathrm{mL}$ cut-off value for week-2 HCV-RNA had the highest sensitivity (86\%) in predicting virological success. Indeed, $23 / 23$ (100\%) patients with undetectable HCV-RNA reached success, versus $26 / 34$ (76.5\%) patients with HCV-RNA $<100 \mathrm{IU} / \mathrm{mL}$, and only $11 / 31$ (35.5\%) with $\mathrm{HCV}-\mathrm{RNA}>100 \mathrm{IU} / \mathrm{mL}$ $(p<0.001)$. Furthermore, differently from failing patients, none of the patient with undetectable HCV-RNA at week-2 had baseline/early resistance.
\end{abstract}

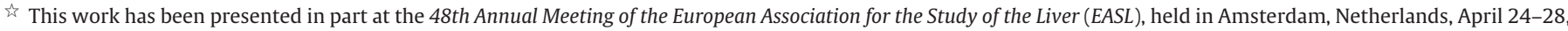
2013 and at The Liver Meeting ${ }^{\circledR} 2014$ American Association for the Study of the Liver, November 1-5, 2013, Washington DC, USA.

* Corresponding author at: Department of Experimental Medicine and Surgery, University of Rome Tor Vergata, Via Montpellier 1, Rome 00133, Italy. Tel.: +39 0672596553; fax: +390672596039 .

E-mail address: ceccherini@med.uniroma2.it (F. Ceccherini-Silberstein). 
Conclusions: With triple therapy based on first generation protease inhibitors, suboptimal HCV-RNA decay at week-2 combined with early detection of resistance can help identifying patients with higher risk of virological failure, thus requiring a closer monitoring during therapy.

(c) 2014 Editrice Gastroenterologica Italiana S.r.l. Published by Elsevier Ltd. All rights reserved.

\section{Introduction}

According to the HCV-kinetics model, initially based on interferon (IFN) monotherapy [1], antiviral treatment of chronic hepatitis $\mathrm{C}$ leads to a biphasic decay of plasma HCV-RNA. Initially, treatment acts by blocking viral production, determining a very fast first phase of HCV-RNA decline characterized by the clearance of free circulating virions. Afterwards, the progressive clearance of infected cells determines a much slower second phase of viraemia decline. This model was later confirmed also in pegylated IFN (pegIFN), pegIFN + ribavirin (RBV) and in treatments including direct acting antiviral agents (DAAs), such as telaprevir (TVR) [2-6].

With IFN treatment, the dividing line between first and second phase was set at day 2 [1], but in the context of TVR-treatment, viral dynamics are much more rapid and the abovementioned line may be moved backwards [3].

TVR and boceprevir (BOC), approved by the U.S. Food and Drug Administration (FDA) and European Medicines Agency (EMA) in 2011, are the first-generation protease inhibitors (PIs) currently available in clinical practice. Both are administered using a response-guided protocol, in which viral decline determines treatment-duration [7-11]. All guidelines set the first viraemia check-point at week-4. Nevertheless, given the rapid HCVdynamics during PI-based triple therapy, earlier time-points may be additionally informative on expected treatment outcome, and therefore become useful in clinical practice.

Moreover, a typical feature of HCV is the ability to develop/select resistance associated variants (RAVs) during treatment, as a consequence of potential natural resistance and low genetic barrier of first-generation PIs [12-14]. Virological-failure to TVR and BOC is indeed associated with RAVs development in the vast majority of cases [15-18].

When RAVs are present at baseline, either as major viral population or as minority variants, they could greatly affect viral response to treatment, particularly in monotherapy, determining a suboptimal viral decay and thus further increasing in resistance level [14,19-26]. This point should be taken into account to fully determine the kinetics of HCV-RNA decay.

In the present study, a large heterogeneous population of patients infected with HCV genotype 1 treated with TVR- or BOC-based triple-therapy was analyzed, in order to investigate HCV-kinetics according to patients' complexity in real-life settings. The kinetics of viral response was assessed shortly after PI's start, and was correlated with both clinical outcome and viral genetic background, focusing on baseline/early detection of RAVs. Several cut-offs categorizing early HCV-RNA decay were then evaluated, in order to provide a useful tool for the monitoring of virological response to first-generation PIs in clinical practice.

\section{Methods}

\subsection{Patients}

Chronically HCV genotype 1 infected patients, consecutively seen at several Italian clinical centres between January 2011 and August 2013 and starting a triple-therapy based on PegIFN/RBV plus BOC or TVR, were considered for inclusion. Only patients with available treatment outcome were considered for the analysis. Exclusion criteria were age under 18 years and other chronic liver diseases. Patients who stopped triple-therapy early for any other reasons than virological breakthrough or stopping rules were also excluded. Treatment schedules and stopping rules followed TVR/BOC prescribing information [8,9]. The choice between a BOC- or TVR-based regimen was at the investigator's discretion.

This study was conducted in accordance with the principles of the Declaration of Helsinki and approved by the local Ethics Committees. All enrolled patients provided written informed consent.

\subsection{Patients monitoring}

Fibrosis staging was determined using either Fibroscan ${ }^{\circledR}$ (Echosens, Paris, France), Fibrotest ${ }^{\circledR}$ (Biopredictive, Paris, France) or liver biopsy, and interpreted by an expert pathologist.

HCV-RNA viral load quantification was performed using the COBASAmpliprep/COBASTaqMan HCV quantitative test v2.0 (Roche Diagnostics) or Abbott RealTime HCV assay (Abbott Laboratories, Abbott Park, IL, USA) with lower limit of detection (LLOD) of 15 and $12 \mathrm{IU} / \mathrm{mL}$, respectively. In addition to standard viraemia check-points [7], HCV-RNA was also determined at $48 \mathrm{~h}$, week-1 and week-2 after PI start (TVR or BOC).

Plasma samples were collected and stored at $-80^{\circ} \mathrm{C}$ after each visit.

\subsection{NS3-protease sequencing}

Genotypic resistance test (GRT) on NS3-protease sequences (aa 1-181) was performed by an home-made population-sequencing protocol as elsewhere described [12]. Baseline-GRT was performed for 110 patients included in the analysis, on the basis of samples' availability. For 39 patients was also available an additional GRT at early time points, between $48 \mathrm{~h}$ and week- 4 of triple-therapy.

The following PI RAVs were considered in the analyses: 36AGLM, 41R, 43ISV, 54ASV, 55IA, 80K, 155IKMQT, 156GSTV, 168AEGNTVY and 170AT.

\subsection{Statistical analysis}

Results are expressed as median values and interquartile range (IQR). Values were compared using the Mann-Whitney U-test.

Sensitivity, specificity and positive predictive values were calculated to evaluate the prediction of virological-success in relation to HCV-RNA values after $48 \mathrm{~h}, 2$ weeks and 4 weeks since PI-start. Correlation coefficient between baseline HCV-RNA and HCV-RNA at $48 \mathrm{~h}$ and at week- 2 of triple therapy was determined using Spearman rank correlation test. A ROC curve analysis was used to determine the optimal HCV-RNA cut-off for treatment outcome prediction.

Linear logistic regression analysis was used to estimate the association between sustained viral response (SVR) and HCV-RNA values at week-2 and week-4 since PI-start, stratified according to the prediction cut-off. HCV-genotype, gender, age, diagnosis of cirrhosis, null-response to previous pegIFN + RBV administrations, 
low baseline viraemia $(\leq 600,000 \mathrm{IU} / \mathrm{mL})$ and presence of at least one baseline/early RAV were used as potential confounders.

All the analyses were performed using the statistical open source environment $R$ (version 3.1.1) and SPSS software package (version 19.0) for Windows (SPSS Inc., Chicago, IL).

\section{Results}

\subsection{Study population}

A total of 287 patients were enrolled for a PI-based treatment $(B O C=79$, TVR $=208)$ (Supp. Fig. S1). Out of these: 84 (29.3\%) prematurely interrupted treatment, due to virological-failure $(48 / 84$, $57.1 \%)$, adverse events $(31 / 84,36.9 \%)$ or poor adherence $(5 / 84$, $6.0 \%) ; 93 / 287(32.4 \%$ ) are still on-treatment, while $110 / 287$ patients (38.3\%) reached End Of Treatment (EOT) with undetectable HCVRNA. Among the EOT patients, 104 (94.5\%) reached SVR, while 6 patients showed a relapse after treatment discontinuation $(\mathrm{BOC}=3, \mathrm{TVR}=3)$. Only patients experiencing either at least $\mathrm{SVR}_{12}$ $(N=104)$ or virological failure $(N=54)$ were considered for the analysis.

Twelve HIV-HCV coinfected patients were included in the study population $(\mathrm{BOC}=2$ and TVR $=10$ ), and 9/12 reached SVR ( 2 TVRtreated coinfected patients resulted partial responders and the third experienced a relapse after TVR discontinuation).

Baseline demographic and virological characteristics of the 158 patients included in the analysis are reported in Table 1. HCV GT1b was the most represented subtype (88/158 patients [55.7\%]), but no statistically significant differences were highlighted between GT-1a and GT-1b for the prevalence of cirrhosis (56.5\% versus $42.0 \%, p=0.072$ ), baseline HCV-RNA (median $[\mathrm{IQR}]=6.0$ [5.4-6.5] $\log \mathrm{IU} / \mathrm{mL}$ versus 5.6 [5.0-6.4] $\log \mathrm{IU} / \mathrm{mL}, p=0.055)$ and baseline ALT values (median $[\mathrm{IQR}]=96[65-140] \mathrm{IU} / \mathrm{mL}$ versus 88 [64-116] IU $/ \mathrm{mL}, p=0.322$ )

Overall, $18.4 \%$ of patients were naïve to anti-HCV treatment. Among treatment-experienced patients, the majority were previous non-responders (83/126, 65.9\%), and 43/126 (34.1\%) were previous relapsers.

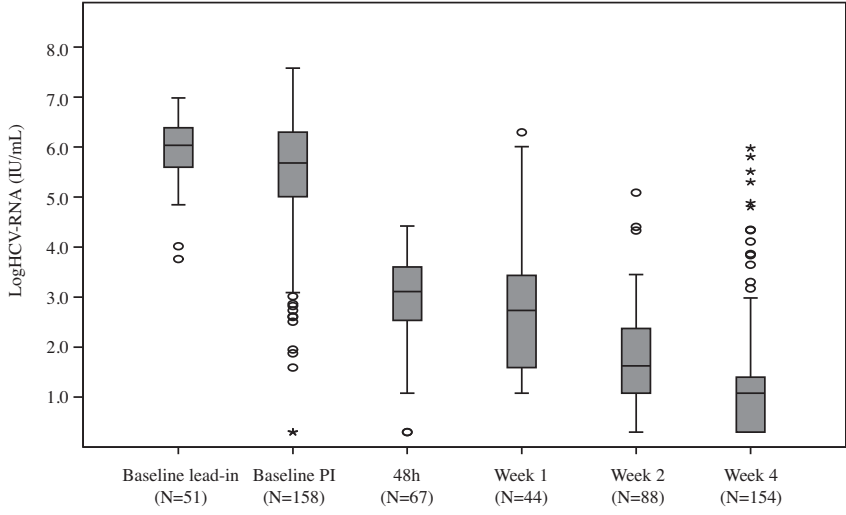

Fig. 1. Box-plots representing the overall distribution of hepatitis $C$ virus RNA values at baseline and at early time points, up to week 4, of triple-therapy administration. IU, international units; PI, protease inhibitor.

\subsection{Early HCV-RNA decay kinetic and its impact on the achievement of a rapid viral response}

A rapid viral response (RVR) was observed in 73/154 (47.4\%) patients with available HCV-RNA at week-4 (34.9\% with BOC and $52.3 \%$ with TVR, $p=0.053)$. Out of 73 RVR-patients, $63(86.3 \%)$ reached then SVR versus 38/81 (46.9\%) non-RVR patients ( $p<0.001)$.

Based on the availability of samples, early time-points after PIstart were analyzed in a subset of patients: $48 \mathrm{~h}$ in 67 patients, and week- 2 in 88 patients. The overall distribution of HCV-RNA values at early time-points, up to week- 4 of triple-therapy administration, is reported in Fig. 1.

After $48 \mathrm{~h}$ of PI-administration, the median (IQR) HCV-RNA decay was of $-3.1(-3.4 ;-2.5) \log \mathrm{IU} / \mathrm{mL}$, corresponding to a median (IQR) weekly viraemia decay-slope of $-10.8(-11.8$; -8.9) $\log \mathrm{IU} / \mathrm{mL}$ per week.

After 48 h, 2 patients had already HCV-RNA below the lower limit of detection (TND). Both of them reached RVR and then SVR. Moreover, RVR was achieved in 22/31 (71.0\%) patients with $48 \mathrm{~h}$ HCV-RNA detectable but $<1000 \mathrm{IU} / \mathrm{mL}$ and $12 / 34$ (35.3\%) patients

Table 1

Baseline clinical characteristics of the 158 protease inhibitor treated patients included in the analysis.

\begin{tabular}{|c|c|c|c|}
\hline & Patients receiving boceprevir & Patients receiving telaprevir & Overall \\
\hline Patients, $N$ & 44 & 114 & 158 \\
\hline Males, $N(\%)$ & $32(72.7)$ & $82(71.9)$ & $114(72.2)$ \\
\hline \multicolumn{4}{|l|}{ HCV-1 subtype, $N(\%)$} \\
\hline $1 \mathrm{a}$ & $17(38.6)$ & $52(45.6)$ & $69(43.7)$ \\
\hline $1 \mathrm{~b}$ & $26(59.1)$ & $62(54.4)$ & $88(55.7)$ \\
\hline $1 \mathrm{~g}$ & $1(2.3)$ & $0(0.0)$ & $1(0.6)$ \\
\hline Age (years), Median (IQR) & $54(45-61)$ & $53(48-61)$ & $53(47-61)$ \\
\hline Patients with unfavourable IL-28B genotype (CT/TT), $N(\%)^{\mathrm{a}}$ & $26(83.9)$ & $67(81.7)$ & $93(82.3)$ \\
\hline Time since HCV diagnosis (years), Median (IQR) & $14(8-18)$ & $16(7-20)$ & $15(7-20)$ \\
\hline \multicolumn{4}{|l|}{ Stage of liver disease, $N(\%)$} \\
\hline F0-F2 & $10(22.7)$ & $28(24.6)$ & $38(24.1)$ \\
\hline F3 & $21(47.7)$ & $23(20.2)$ & $44(27.8)$ \\
\hline Cirrhosis (F4) & $13(29.5)$ & $63(55.3)$ & $76(48.1)$ \\
\hline Naive patients, $N(\%)$ & $3(6.8)$ & $26(22.8)$ & $29(18.4)$ \\
\hline \multicolumn{4}{|l|}{ Virological outcome to previous SOC, $N(\%)$} \\
\hline Non-responder & $9(20.5)$ & $8(7.0)$ & $17(10.8)$ \\
\hline Null-responder & $14(31.8)$ & $25(21.9)$ & $39(24.7)$ \\
\hline Partial-responder & $8(18.2)$ & $19(16.7)$ & $27(17.1)$ \\
\hline Relapse & $10(22.7)$ & $33(28.9)$ & $43(27.2)$ \\
\hline Unknown & $0(0.0)$ & $3(2.6)$ & $3(1.9)$ \\
\hline Baseline Lead-in HCV-RNA (log IU/mL), Median (IQR) & $6(5.5-6.6)$ & $6.1(5.9-6.2)^{\mathrm{b}}$ & $6.1(5.6-6.5)$ \\
\hline Baseline PI HCV-RNA $(\log \mathrm{IU} / \mathrm{mL})$, Median $(\mathrm{IQR})^{\mathrm{c}}$ & $5.1(3.7-5.7)$ & $6(5.5-6.6)$ & $5.8(5.1-6.4)$ \\
\hline Baseline ALT, Median (IQR) & $86(50-117)$ & $92(65-122)$ & $90(64-122)$ \\
\hline
\end{tabular}

$\mathrm{HCV}$, hepatitis C virus; IQR, interquartile range; SOC, standard of care; IU, international units; PI, protease inhibitor; ALT, alanine transaminase.

a IL-28B genotype was available for 31 boceprevir-treated patients and for 82 telaprevir-treated.

b A 4-weeks sensitivity test with peg-interferon + ribavirin was performed in eight patients before telaprevir start.

${ }^{\text {c }}$ Hepatitis C virus RNA value before protease inhibitor start. 
Table 2

Triple-therapy outcome in relation to $48 \mathrm{~h}$ and week 2 hepatitis C virus RNA values.

\begin{tabular}{|c|c|c|c|c|c|c|c|c|}
\hline & \multicolumn{3}{|c|}{ HCV-RNA at $48 \mathrm{~h}(\mathrm{IU} / \mathrm{mL})$} & \multirow[t]{2}{*}{$p$-value ${ }^{a}$} & \multicolumn{3}{|c|}{ HCV-RNA at week 2 (IU/mL) } & \multirow[t]{2}{*}{$p$-value } \\
\hline & TND & $<1000$ & $>1000$ & & TND & $<100$ & $>100$ & \\
\hline Patients with available HCV-RNA value, $N$ & 2 & 31 & 34 & & 23 & 34 & 31 & \\
\hline Patients experiencing RVR, $N(\%)^{\mathrm{a}}$ & $2(100)$ & $22(71.0)$ & $12(35.3)$ & 0.004 & $23(100)$ & $19(55.9)$ & $3(9.7)$ & $<0.001$ \\
\hline Patients experiencing SVR, $N(\%)$ & $2(100)$ & $25(80.6)$ & $20(58.8)$ & 0.102 & $23(100)$ & $26(76.5)$ & $11(35.5)$ & $<0.001$ \\
\hline Patients experiencing virological failure, $N(\%)^{\mathrm{b}}$ & - & $6(19.4)$ & $14(41.2)$ & 0.102 & - & $8(23.5)$ & $20(64.5)$ & $<0.001$ \\
\hline Virological breakthrough, $N(\%)$ & - & $6(100)$ & $13(92.9)$ & & - & $6(75.0)$ & $20(100)$ & \\
\hline Relapse, $N(\%)$ & - & - & $1(7.1)$ & & - & $2(25.0)$ & - & \\
\hline
\end{tabular}

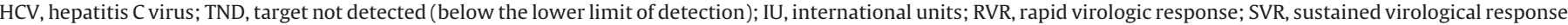

a $P$-value was calculated by Chi Square test for trend.

with $48 \mathrm{~h}$ HCV-RNA $>1000 \mathrm{IU} / \mathrm{mL}(p=0.004)$ (Table 2$)$. The absolute value of HCV-RNA at $48 \mathrm{~h}$ was independent by HCV-genotype, previous response to pegIFN + RBV dual-therapy and diagnosis of cirrhosis (Fig. 2, panel A), as well as by the type of PI used ( $p=0.905$ by Mann-Whitney test, data not shown).

At week-2, viraemia slope continued to diminish as patients approached undetectability, following a classical biphasic kinetics. Indeed, the median (IQR) HCV-RNA decay was of -4.1 ( -4.9 ; -3.6) $\log \mathrm{IU} / \mathrm{mL}$ and the weekly viraemia decay-slope reached a median (IQR) value of $-2.1(-2.4 ;-1.8) \log \mathrm{IU} / \mathrm{mL}$ per week, thus much slower compared to that estimated at $48 \mathrm{~h}$. At week-2, 31/88 (35.2\%) patients still had viraemia $>100 \mathrm{IU} / \mathrm{mL}$ (Table 2 ): $87.1 \%$ (27/31) of them were previous non-responders, supporting the significantly slower second phase kinetic observed in this category of subjects versus previous relapsers or naïve $(p=0.002$; Fig. 2, panel A). Interestingly, only $3 / 31$ (9.7\%) patients with HCVRNA $>100 \mathrm{IU} / \mathrm{mL}$ at week-2 experienced an RVR afterwards, versus $23 / 23$ TND patients ( $p<0.001$ by Fisher exact test) (Table 2 ).

Therefore, early determination of HCV-RNA at $48 \mathrm{~h}$ and week2 already allows the identification of: (a) patients with higher chances of reaching RVR and (b) patients with suboptimal viralresponse. No differences were highlighted in early HCV-RNA levels following TVR or BOC administration.

\subsection{Impact of early HCV-RNA decay kinetic on treatment} outcome

HCV-RNA value at week-2 was significantly associated with virological-outcome, being lower in patients reaching SVR (median [IQR] HCV-RNA ${ }_{2 \mathrm{w}}=1.2[0.3-1.7]$ ) in comparison to those experiencing virological-failure (median [IQR] HCV-RNA $2 \mathrm{w}=2.3$ [1.9-2.8]; $p<0.001$ by Mann-Whitney $U$ test) (Fig. 2, panel B). On the contrary, HCV-RNA value at $48 \mathrm{~h}$ did not reach statistical significance $(p=0.139)$ (Fig. 2, panel B).

In particular, virological-failure was never observed in 23 TND patients at week-2 (4 BOC and 19 TVR), whereas it occurred in 8/34 patients (23.5\%) with $\leq 100 \mathrm{IU} / \mathrm{mL}$ ( 1 BOC and 7 TVR) and in 20/31 patients (64.5\%) (7 BOC and 13 TVR) with $>100 \mathrm{IU} / \mathrm{mL}$ at week-2 ( $p<0.001$ by Chi $^{2}$ Test for Trend) (Table 2). Notably, in our population, only 1 RVR patient experienced virological-failure, and he had $\mathrm{HCV}-\mathrm{RNA}=430 \mathrm{IU} / \mathrm{mL}$ at week-2.

\subsection{Determinants of early HCV-RNA decay during PI administration}

The rapid HCV-RNA decays observed at both $48 \mathrm{~h}$ and week2 of triple-therapy administration were highly homogenous in
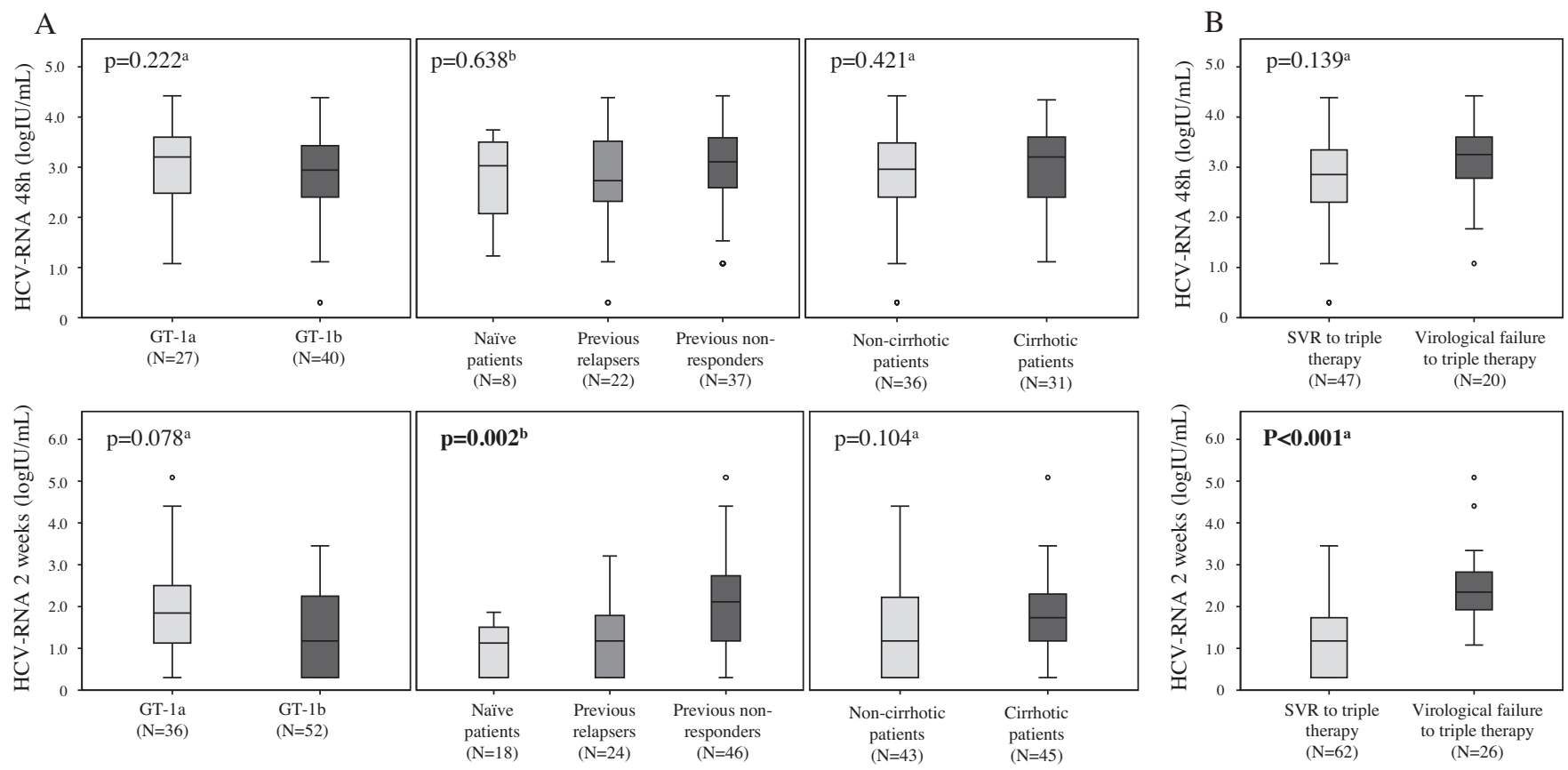

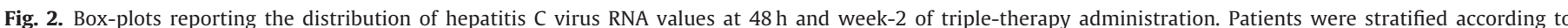

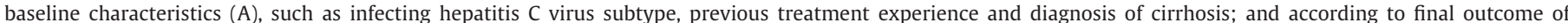

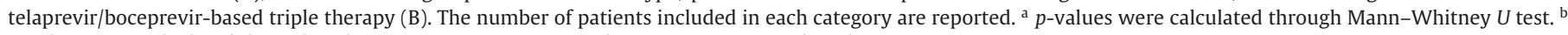
p-values were calculated through Wilcoxon-Test. IU, international units; SVR, sustained viral response. 


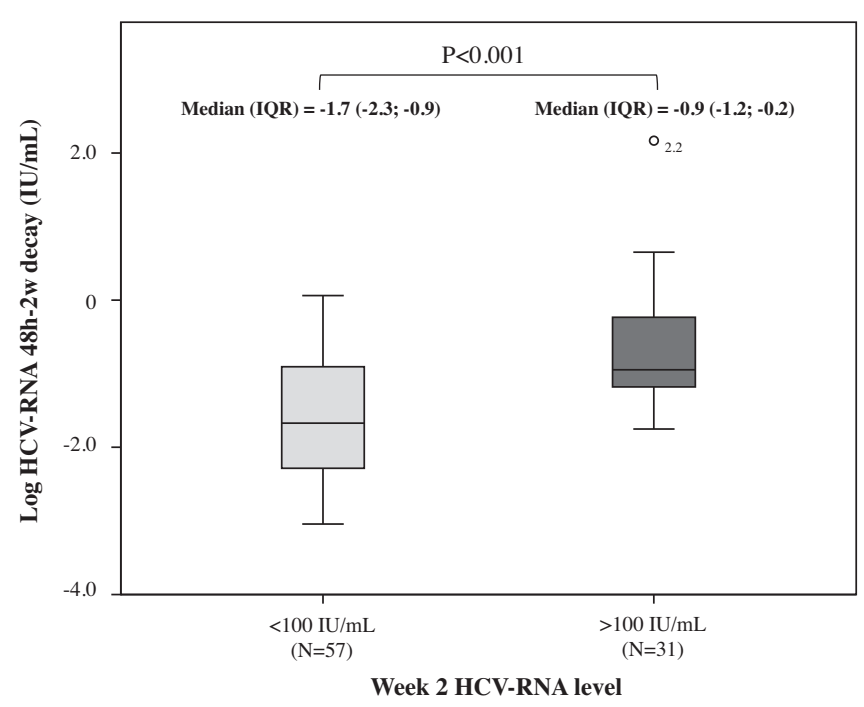

Fig. 3. Box-plot representing the logarithmic hepatitis $C$ virus RNA decay between $48 \mathrm{~h}$ and week-2 of triple-therapy administration in patients with hepatitis $\mathrm{C}$ virus RNA at week-2 lower or higher than $100 \mathrm{IU} / \mathrm{mL}$. The number of patients included in each category are reported. P-value was calculated through Mann-Whitney $U$ test. $\mathrm{IU}$, international units; IQR, interquartile range.

all patients analyzed, irrespective of HCV-genotype ( $p=0.848$ and $p=0.849$ by Mann-Whitney $U$ test, respectively), previous treatment outcome $(p=0.367$ and $p=0.831$ by Kruskal-Wallis test, respectively), and diagnosis of cirrhosis $(p=0.505$ and $p=0.753$ by Mann-Whitney $U$ test, respectively) (Supp. Fig. S2, panels A and $\mathrm{B})$.

Since the observed viraemia decays from baseline-to- $48 \mathrm{~h}$ and from baseline-to-week-2 were homogeneous, the absolute values of $48 \mathrm{~h}$ and week-2 HCV-RNA were expected to depend upon baseline viraemia. Indeed, Spearman correlation test confirmed a strong positive association of HCV-RNA at these early time-points with baseline values. This indicates that, by increasing baseline viraemia, also viraemia at early time points consensually increase, with a stronger concordance at $48 \mathrm{~h}$ (linear correlation coefficient $=0.61, p<0.001$ ) in comparison to week-2 (linear correlation coefficient $=0.51, p<0.001$ ). The reason for this difference could lie in the observation that HCV-RNA value at week-2 was not only dependent upon baseline viraemia, but also on the slope of second-phase HCV-RNA decay. Indeed, the median (IQR) HCVRNA 48 h-week 2 decay was $-0.9(-1.2 ;-0.2) \log \mathrm{IU} / \mathrm{mL}$ in patients with $>100 \mathrm{IU} / \mathrm{mL}$ at week-2 and $-1.7(-2.3 ;-0.9) \log \mathrm{IU} / \mathrm{mL}$ in patients with $<100 \mathrm{IU} / \mathrm{mL}$ ( $p<0.001$ by Mann-Whitney $U$ test) (Fig. 3).

\subsection{Predictive value of HCV-RNA determination after $48 \mathrm{~h}$ and 2 weeks of triple-therapy}

To identify the optimal HCV-RNA value (at both $48 \mathrm{~h}$ and week2 time-points) able to discriminate virological-outcome, both in terms of sensitivity and specificity, ROC curve analyses have been performed. ROC curve analysis identified a week-2 HCV-RNA value of $100 \mathrm{IU} / \mathrm{mL}$ as an optimal cut-off in predicting SVR (sensitivity $=81 \%$, specificity $=71 \%$ ). Overall, the positive predictive value for HCV-RNA $<100 \mathrm{IU} / \mathrm{mL}$ at week-2 of triple-therapy was of $86 \%$.

At $48 \mathrm{~h}$, ROC curve analysis identified as optimal cut-off for sensitivity in predicting SVR an HCV-RNA value of $1000 \mathrm{IU} / \mathrm{mL}$. Nevertheless, this optimized cut-off of HCV-RNA at $48 \mathrm{~h}$ of triple therapy had lower sensitivity and specificity in predicting SVR(sensitivity $=57 \%$, specificity $=70 \%$ ) in comparison to HCV-RNA cut-off of $100 \mathrm{IU} / \mathrm{mL}$ at week-2, reaching a positive predictive value of $82 \%$.

The achievement of RVR had the best specificity in predicting SVR ( $81 \%$ ), but sensitivity was lower respecting to week-2 cut-off of $100 \mathrm{IU} / \mathrm{mL}$ (63\% versus $81 \%$, respectively). Positive predictive value was identical to that obtained with week-2 cut-off (86\%).

Therefore, in our study population, for SVR prediction, the use of $100 \mathrm{IU} / \mathrm{mL}$ cut-off at week-2 seems to be the most suitable in comparison to $1000 \mathrm{IU} / \mathrm{mL}$ cut-off at $48 \mathrm{~h}$ and detectable HCV-RNA values at week-4.

By univariable logistic regression analysis, HCV-RNA $\leq$ $100 \mathrm{IU} / \mathrm{mL}$ at week-2 was also a strong predictor of SVR (Odds Ratio, OR $[\mathrm{CI}]=13.0$ [4.1-41.4], $p<0.001$ ) (Table 3), even stronger than the achievement of an RVR (OR $[\mathrm{CI}]=8.5$ [2.5-28.8], $p<0.001)$. Notably, the association between HCV-RNA value $\leq 100 \mathrm{IU} / \mathrm{mL}$ and virological success was also confirmed by multivariable analysis (OR [CI] = 20.3 [2.7-152.7], $p=0.003$ ) (Table 3), after correction by baseline/early detection of resistance, gender, age, HCV-genotype, cirrhosis, previous null-response to pegIFN + RBV and low baseline viraemia $(\leq 600,000 \mathrm{IU} / \mathrm{mL}$ ). Also the RVR correlation with SVR was confirmed after correction by confounding variables $(\mathrm{OR}[\mathrm{CI}]=18.7$ [2.2-157.5], $p=0.007)$. Among confounder variables, also female gender was significantly associated with success by multivariable analysis analysis (OR $[\mathrm{CI}]=11.0$ [1.2-99.3], $p=0.032$ ) (Table 3). Probably due to the high number of missing values, unfavourable IL-28B genotype (CT or TT) was not significantly associated with success by univariable analysis (OR $[\mathrm{CI}]=0.2[0.0-1.9], p=0.64$, data not shown), and it was not considered as confounder variable in multivariable analysis.

\subsection{Baseline/early resistance and early virological response}

None of the patients with undetectable HCV-RNA at week-2 presented evidences of baseline/early RAVs by population sequencing (0/17 and 0/8 with available GRT at baseline and within the first 4 weeks of PI administration, respectively). All these patients are $\mathrm{SVR}_{12}$. On the contrary, at least one baseline/early RAV was found

Table 3

Univariable and multivariable logistic regression models for association with virological success to triple therapy.

\begin{tabular}{|c|c|c|c|c|c|c|c|c|}
\hline \multirow[t]{2}{*}{ Characteristic } & \multirow[t]{2}{*}{ Crude OR } & \multicolumn{2}{|c|}{ 95\% C.I. } & \multirow[t]{2}{*}{$p$-value } & \multirow[t]{2}{*}{ Adjusted OR } & \multicolumn{2}{|l|}{ 95\% C.I. } & \multirow[t]{2}{*}{$p$-value } \\
\hline & & Lower & $\overline{\text { Upper }}$ & & & Lower & $\overline{\text { Upper }}$ & \\
\hline HCV-RNA $\leq 100 \mathrm{IU} / \mathrm{mL}$ at week 2 & 13.0 & 4.1 & 41.4 & $<0.001$ & 20.3 & 2.7 & 152.7 & 0.003 \\
\hline At least one baseline/early resistance mutation & 0.6 & 0.2 & 2.2 & 0.441 & 0.5 & 0.1 & 2.7 & 0.389 \\
\hline Gender (male versus female) & 2.7 & 0.9 & 8.3 & 0.083 & 11.0 & 1.2 & 99.3 & 0.032 \\
\hline Age ( 1 year higher) & 1.0 & 0.9 & 1.1 & 0.234 & 1.0 & 0.9 & 1.1 & 0.307 \\
\hline HCV genotype (1a versus $1 \mathrm{~b}$ ) & 1.5 & 0.6 & 4.1 & 0.397 & 0.8 & 0.1 & 4.0 & 0.743 \\
\hline Cirrhosis (yes versus no) & 1.0 & 0.4 & 2.6 & 0.975 & 0.6 & 0.1 & 2.7 & 0.500 \\
\hline Previous null responder to SOC & 0.5 & 0.2 & 1.4 & 0.158 & 2.6 & 0.3 & 20.3 & 0.355 \\
\hline Baseline $\mathrm{VL} \leq 600,000 \mathrm{IU} / \mathrm{mL}$ & 2.3 & 0.8 & 6.4 & 0.116 & 1.4 & 0.3 & 7.9 & 0.672 \\
\hline
\end{tabular}

HCV, hepatitis C virus; OR, odds ratio; C.I., confidence interval; SOC, standard of care; VL, viral load; IU, international units. 
in $14 / 47$ patients with detectable HCV-RNA at week-2 ( $p=0.001$ by Fisher exact test).

At baseline, as expected, RAVs were detected more frequently in patients infected with GT-1a (15/50,30.0\%) than in GT-1b (3/56, $5.4 \%$ ). The most common detected baseline RAV was the Q80K, found in $11 / 110(10.0 \%, 9 / 11 \mathrm{GT}-1 \mathrm{a})$ patients analyzed, followed by T54S in 4/110 (3.6\%, 2/4 GT-1a). In addition, one GT-1a patient showed the co-presence of V36L+Q80K RAVs. Virological failure was observed in 5/11 patients with baseline Q80K (all GT-1a), 3/4 patients with T54S and in the patient with V36L + Q80K.

De novo RAVs development at early time-points was observed in $7 / 39(17.9 \%)$ patients. All had HCV-RNA detectable at week-2 and 5/7 experienced virological failure.

Overall, RAVs either at baseline or de novo developed during PIadministration have been exclusively observed in patients showing detectable HCV-RNA values at week-2, while they were absent in all patients reaching undetectable HCV-RNA values at this time-point. The combination of resistance and slower virological response can thus play a synergic role in determining treatment failure.

\section{Discussion}

The present study analyzes the clinical usefulness of early viral response to TVR or BOC treatment in a large and heterogeneous population of patients infected with HCV genotype 1 . We found that, independently from the PI employed, a $100 \mathrm{IU} / \mathrm{mL}$ cut-off of HCV-RNA at week-2 of triple therapy was able to discriminate patients with increased risk of virological-failure from patients who, despite hepatic impairment or previous treatment experience, are most likely to reach therapeutic success.

It is well known that HCV-RNA decay during antiviral treatment follows a biphasic profile, as a consequence of the administration of drugs which act by blocking viral production $[1,3]$. The block of de novo virion production from infected hepatocytes determines a rapid first phase of HCV-RNA decline in serum. A slower second phase mainly depends upon the clearance of infected cells, mediated through death or loss of replicative intermediates [3]. PI-based triple therapy was associated with a deeper and faster first-phase, as well as with a faster second-phase, compared to regimens notincluding a DAA $[3,27,28]$.

In this study, we found that the first-phase decline, classically comprised within the first $48 \mathrm{~h}$ of triple-therapy administration, was indeed very intense and, furthermore, highly homogeneous among all patients analyzed. Baseline clinical characteristics had no impact on this first-phase decline, and HCV-RNA values at $48 \mathrm{~h}$ were correlated only with baseline HCV-RNA values. This early HCV-RNA kinetics was also comparable among the two PIs, supporting previous results indicating that therapy with a lead-in phase followed by addition of a single DAA achieves a similar early HCV-RNA reduction as including the DAA from the beginning [29].

Recently, we showed that telaprevir administration in difficultto-treat patients (i.e. previous non responders or cirrhotic) leads to a slower second-phase decline in respect to naïve, noncirrhotic patients [6]. Interestingly, the second phase decline was particularly compromised in those who experienced virologicalbreakthrough, and resulted in higher HCV-RNA values at week-2 of PI-based triple therapy.

Similarly, also in our wider population, patients with detectable HCV-RNA at week-2 more frequently experienced virologicalfailure to triple-therapy, either containing BOC or TVR. Indeed, virological-failure was observed in $64.5 \%$ of patients with $\mathrm{HCV}$ RNA $>100 \mathrm{IU} / \mathrm{mL}$ at week-2 versus $0 \%$ in those with undetectable HCV-RNA values.

In our study population, two main mechanisms cooperated in determining HCV-RNA levels at week-2 of triple-therapy: (a) baseline viraemia values and (b) the slope of second-phase ( $48 \mathrm{~h}$-week 2) viraemia decline. High baseline viraemia is a known risk factor for virological-failure [30,31], and thus its correlation with lower responsiveness is not surprising. The slope of second phase decline, on the other hand, directly depends on treatment efficacy, as previously demonstrated [3]. This correlation was confirmed in this study, since patients with higher week-2 viraemia were, in the majority of cases, those with poor sensitivity to IFN (previous non-responders).

Overall, the determination of HCV-RNA at week-2 of tripletherapy was highly sensitive in predicting SVR, and allowed the identification of patients with outstanding viral-response. Indeed, in our study, at week-2, 23/88 (26.1\%) patients had undetectable HCV-RNA, with 23/23 (100\%) patients reaching an RVR and SVR afterwards, versus only $3 / 31$ (9.7\%) RVR and 11/31 (35.5\%) SVR among patients with HCV-RNA $>100 \mathrm{IU} / \mathrm{mL}$. Moreover, 6 cirrhotic patients and 4 patients previously non-responder to dual therapy had undetectable viraemia at week-2, and notably all of them achieved SVR.

The cut-off set at $100 \mathrm{IU} / \mathrm{mL}$ for HCV-RNA at week-2 of tripletherapy showed the highest sensitivity in predicting SVR among other early HCV-RNA assessments, including the achievement of an RVR, with a positive predictive value of $86 \%$. The strength of this correlation among HCV-RNA $\leq 100 \mathrm{IU} / \mathrm{mL}$ at week-2 and SVR was also confirmed by regression analysis. Indeed, this early viraemia check-point was found to be a predictor of SVR as good as the achievement of an RVR, even after correction by the most common clinical and viral parameters classically involved in sensitivity to first-generation PIs administration.

Our current study shows also that the analysis of NS3 sequence at baseline may further strengthen the ability to identify patients with higher probability of success. Indeed, baseline presence of RAVs (including the Q80K) or early development were exclusively observed in patients with still detectable HCV-RNA at week-2, and the association of RAVs with suboptimal HCV-RNA decay uncovered a condition of higher risk of virological-failure, suggesting the need for a close virological follow-up.

Pharmacoeconomic analyses and clinical studies suggest that the "cost per SVR" still favours the use of pegIFN-RBV dual-therapy, rather than PI-based triple-therapy, in patients complying "easyto-treat criteria", such as those who exhibit excellent viral response during the first 4 weeks of treatment with pegIFN and RBV alone [30,32-35]. On the other hand, for patients who do not fully comply with predictors of viral-response (i.e. being drug-naïve, non-cirrhotic, low baseline HCV-RNA, preferentially IL28-B non-TT and achieving an RVR), additional evaluation of HCV-RNA at early time-points during PI-based triple-therapy could actually limit: (a) the risk of failure with the development of RAVs [17]; (b) the onset of serious adverse events; and (c) costs related to drugs and management of complications.

Overall, this study has its strengths and limitations. Even if this is the largest study, to our knowledge, analyzing early viral-kinetics with first-generation PIs in clinical practice, the predictive values of early HCV-RNA decay could change by analyzing a wider population. The ad interim nature of this study also accounts for a quite high rate of virological-failure observed (54/158 [34.2\%]). Indeed, even if the majority of patients started treatment fairly close together, treatment-failures generally occur after few weeks of therapy, while a longer period of time is necessary for the SVR evaluation, therefore resulting in an underestimation of its frequency. For this reason, the overall SVR rates should not be yet extrapolated in this study, and indeed the assessment of treatment efficacy was not an endpoint.

In conclusion, due to the rapid evolution of treatment scenarios with different efficacy and costs, it is important to implement tailored treatments. The present study provides a proof of concept, to 
be confirmed on different populations and on a longer time span, that a rapid early HCV-RNA decay, with undetectable HCV-RNA at 2 weeks after first-generation PI initiation, may allow to predict a good therapeutic outcome, even in difficult-to-treat patients. On the contrary, a suboptimal early decay, especially if associated with the development of RAVs, speaks in favour of a highly probable virological failure.

\section{Conflict of interest}

A. Gasbarrini, A. Di Biagio, M. Angelico, C.F. Perno and F. CeccheriniSilberstein have no conflict of interest with respect to this manuscript, however: A. Gasbarrini has received prior consultancy honoraria from MSD, gilead, jansenn, abbvie, alfawassermann. A. Di Biagio has received prior research funding and/or consultancy honoraria from Bristol Myers Squibb, Gilead, Janssen, Merck Sharp \& Dohme, Roche, and ViiV. M. Angelico has received funds for attending symposia, speaking, organizing educational activities, grant research support and consultancy from Roche, Gilead, Merck Sharp \& Dohme, Janssen Cilag. C.F. Perno has received funds for attending symposia, speaking, organizing educational activities, grant research support, consultancy and advisory board membership, from Abbott, Boehringer Ingelheim, Bristol Myers Squibb, Gilead, Merck Sharp \& Dohme, Janssen Cilag, Pfizer, Tibotec, Roche, and ViiV. F. Ceccherini-Silberstein has received funds for attending symposia, speaking, organizing educational activities, grant research support, consultancy and advisory board from AbbVie, Merck Sharp \& Dohme, Gilead, Janssen Cilag, Roche, Bristol Myers Squibb, and ViiV. The other authors of this study do not have anything to disclose regarding funding from industry or conflict of interest with respect to this manuscript.

\section{Acknowledgements}

This work was supported by the Italian Ministry of Instruction, University and Research (MIUR) (Accordi di Programma 2011: RBAP11YS7K_001 [HIRMA], Bandiera InterOmics Protocollo PB05 $1^{\circ}$ ), by Merck Sharpe \& Dohme and by Aviralia Foundation. The funders had no role in study design, data collection and analysis, decision to publish, or preparation of the manuscript.

We thank Roche and Abbott for providing laboratory material for HCV-RNA determination, the Clinical Hepatology and Molecular Virology groups of “Tor Vergata” University Hospital, and particularly Francesca Stafoggia for technical support.

\section{Appendix A. Supplementary data}

Supplementary data associated with this article can be found, in the online version, at http://dx.doi.org/10.1016/j.dld.2014.11.010.

\section{References}

[1] Neumann AU, Lam NP, Dahari $H$, et al. Hepatitis C viral dynamics in vivo and the antiviral efficacy of interferon-alpha therapy. Science 1998;282:103-7.

[2] Dixit NM, Layden-Almer JE, Layden TJ, et al. Modelling how ribavirin improves interferon response rates in hepatitis C virus infection. Nature 2004;432:922-4.

[3] Guedj J, Perelson AS. Second-phase hepatitis C virus RNA decline during telaprevir-based therapy increases with drug effectiveness: implications for treatment duration. Hepatology 2011;53:1801-8.

[4] Powers KA, Dixit NM, Ribeiro RM, et al. Modeling viral and drug kinetics: hepatitis $C$ virus treatment with pegylated interferon alfa-2b. Seminars in Liver Disease 2003;23(Suppl. 1):13-8.

[5] Shudo E, Ribeiro RM, Perelson AS. Modelling the kinetics of hepatitis C virus RNA decline over 4 weeks of treatment with pegylated interferon alpha-2b. Journal of Viral Hepatitis 2008;15:379-82.

[6] Cento V, Di Maio C, Valenti F, et al. HCV kinetics and quasispecies evolution within the first hours of telaprevir triple therapy in difficult-to-treat HCV-infected patients. The Liver Meeting 2013, AASLD Abstracts. Hepatology 2013;58(Suppl. 1):939A\#1509.
[7] EASL Recommendations on Treatment of Hepatitis C. International Liver Congress $^{\mathrm{TM}} 2014 ; 2014$.

[8] European Medicines Agency (EMA). Incivek (telaprevir) Film Coated Tablets. EU Prescribing Information. 2011 May 1.

[9] European Medicines Agency (EMA). Victrelis (boceprevir) Capsules. EU Prescribing Information. 2011 May 1.

[10] Associazione Italiana per lo Studio del Fegato. Indicazioni e gestione dei trattamenti anti-HCV nei pazienti con epatite cronica: linee di indirizzo dell'Associazione Italiana per lo Studio del Fegato (AISF). 31-3-0014.

[11] Bruno S, Bollani S, Zignego AL, et al. Undetectable HCV-RNA at treatment-week 8 results in high-sustained virological response in HCV G1 treatment-experienced patients with advanced liver disease: the International Italian/Spanish Boceprevir/Peginterferon/Ribavirin Name Patients Program. Journal of Viral Hepatitis 2014 [Epub ahead of print].

[12] Cento V, Mirabelli C, Salpini R, et al. HCV genotypes are differently prone to the development of resistance to linear and macrocyclic protease inhibitors. PLoS ONE 2012; 7:e39652.

[13] Delang L, Vliegen I, Froeyen M, et al. Comparative study of the genetic barriers and pathways towards resistance of selective inhibitors of hepatitis $C$ virus replication. Antimicrobial Agents and Chemotherapy 2011;55:4103-13.

[14] Rong L, Dahari H, Ribeiro RM, et al. Rapid emergence of protease inhibitor resistance in hepatitis C virus. Science Translational Medicine 2010;2:30-2.

[15] Jacobson IM, McHutchison JG, Dusheiko G, et al. Telaprevir for previously untreated chronic hepatitis C virus infection. New England Journal of Medicine 2011:364:2405-16.

[16] Zeuzem S, Andreone P, Pol S, et al. Telaprevir for retreatment of HCV infection. New England Journal of Medicine 2011;364:2417-28.

[17] Pawlotsky JM. Treatment failure and resistance with direct-acting antiviral drugs against hepatitis C virus. Hepatology 2011;53:1742-51.

[18] Halfon P, Locarnini S. Hepatitis C virus resistance to protease inhibitors. Journal of Hepatology 2011;55:192-206.

[19] Bartels DJ, Zhou Y, Zhang EZ, et al. Natural prevalence of hepatitis C virus variants with decreased sensitivity to NS3.4A protease inhibitors in treatment-naive subjects. Journal of Infectious Diseases 2008;198: 800-7.

[20] Cento V, Di Maio VC, Di Paolo D, et al. NS3-resistance in advanced HCV patients treated with BOC/TRV-based therapy: impact on virological failure of baseline and early time points. The Liver Meeting 2013, AASLD Abstracts. Hepatology 2013;58(Suppl. 1):1156A\#1960.

[21] Franco S, Bellido R, Aparicio E, et al. Natural prevalence of HCV minority variants that are highly resistant to NS3/4A protease inhibitors. Journal of Viral Hepatitis 2011;18:e578-82.

[22] Lopez-Labrador FX, Moya A, Gonzalez-Candelas F. Mapping natural polymorphisms of hepatitis C virus NS3/4A protease and antiviral resistance to inhibitors in worldwide isolates. Antiviral Therapy 2008;13:481-94.

[23] Vallet S, Viron F, Henquell C, et al. NS3 protease polymorphism and natural resistance to protease inhibitors in French patients infected with HCV genotypes 1-5. Antiviral Therapy 2011;16:1093-102.

[24] Vicenti I, Rosi A, Saladini F, et al. Naturally occurring hepatitis C virus (HCV) NS3/4A protease inhibitor resistance-related mutations in HCV genotype 1-infected subjects in Italy. Journal of Antimicrobial Chemotherapy 2012;67:984-7.

[25] Ogert RA, Howe JA, Vierling JM, et al. Resistance-associated amino acid variants associated with boceprevir plus pegylated interferon-alpha2b and ribavirin in patients with chronic hepatitis C in the SPRINT-1 trial. Antiviral Therapy 2013:18:387-97.

[26] Izquierdo L, Helle F, Francois C, et al. Simeprevir for the treatment of hepatitis C virus infection. Pharmacogenomics and Personalized Medicine 2014;7:241-9.

[27] Chatterjee A, Smith PF, Perelson AS. Hepatitis C viral kinetics: the past, present, and future. Clinics in Liver Disease 2013:17:13-26.

[28] Chatterjee A, Guedj J, Perelson AS. Mathematical modelling of HCV infection: what can it teach us in the era of direct-acting antiviral agents. Antiviral Therapy 2012:17(6 Pt B):1171-82.

[29] Rong L, Guedj J, Dahari H, et al. Treatment of hepatitis C with an interferon-based lead-in phase: a perspective from mathematical modelling. Antiviral Therapy 2014;19:469-77.

[30] Andriulli A, Di M, Margaglione VM, et al. Identification of naive HCV-1 patients with chronic hepatitis who may benefit from dual therapy with peg-interferon and ribavirin. Journal of Hepatology 2014;60:16-21

[31] Berg T, Sarrazin C, Herrmann E, et al. Prediction of treatment outcome in patients with chronic hepatitis C: significance of baseline parameters and viral dynamics during therapy. Hepatology 2003;37:600-9.

[32] Pearlman BL, Ehleben C. Hepatitis C genotype 1 virus with low viral load and rapid virologic response to peginterferon/ribavirin obviates a protease inhibitor. Hepatology 2014;59:71-7.

[33] Serfaty L. Is there still a role for PEG IFN + RBV therapy in patients with HCV genotype 1? Liver International 2014;34(Suppl. 1):11-2.

[34] Camma C, Petta S, Cabibbo G, et al. Cost-effectiveness of boceprevir or telaprevir for previously treated patients with genotype 1 chronic hepatitis C. Journal of Hepatology 2013;59:658-66

[35] Camma C, Petta S, Enea M, et al. Cost-effectiveness of boceprevir or telaprevir for untreated patients with genotype 1 chronic hepatitis C. Hepatology 2012;56:850-60. 